\title{
Comprehensive Case Study Program of Ethics Course Based on the Blended Learning Model and its Impact on Active Learning Indicators
}

leili mosalanejad ( $\sim$ saedparsa2012@gmalL.COM )

jahrom university of medical sciences

Atefeh karamzadeh

Shiraz University of Medical Sciences Faculty of Dentistry

Leila Bazrafkan

University of Shiraz: Shiraz University

Research article

Keywords: OSCE, Medical education, Medical ethics, Self-direction, Self-regulation, Active learning, Combined learning, Flex model, Case-based study, Professionalism

Posted Date: December 17th, 2020

DOI: https://doi.org/10.21203/rs.3.rs-127877/v1

License: (c) (i) This work is licensed under a Creative Commons Attribution 4.0 International License. Read Full License 


\section{Abstract}

\section{Background}

Now in training physicians, should be pay attention to medical education and clinical skills with respect to justice, dignity and human rights. This is the ultimate goal of medical ethics. The purpose of this study is a comprehensive case study educational program of ethics course based on blended learning model and its effect on indicators of active learning.

\section{Methods}

This quasi-experimental intervention study was performed on 70 physiopathology medical students who had taken medical ethics course. The students' educational program included teaching theoretical topics of medical ethics, discussing ethical issues and clinical reasoning on cases, discussing in forum environment and individual assignments in LMS system and completing portfolio. Student evaluation was associated with evaluating the effect of method on students' knowledge, attitude and ethical reasoning skills. The impact of intervention on self-directed learning and self-regulation was also investigated. Data collection tools were Gaglimino (1978) and Beauford (1995) self-directed readiness questionnaires that students answered before and after their intervention. . Data analysis was performed using SPSS software at two levels of descriptive and analytic statistics.

\section{Results}

The results showed that there was a significant difference between students 'self-direction after the intervention compared to before the intervention $(p=0.005)$. but, students' self-regulation was not significant despite the increase after the intervention $(p=0.149)$. Also, the total score of students in intervention group were significant compared to traditional group $(p<.05)$.

\section{Conclusion}

According to research findings, it is suggested that while considering student-centered educational approaches based on case study, the use of blended learning in medical ethics course, can have a positive effects on improving students' learning and individual learning indicators (self-regulation and self-directed learning). Using those method suggest in other medical courses.

\section{Background}

Incompatibility of some trainings in traditional system of medical education is one of the challenges of general medical training in the Iranian educational system (1). In traditional education system, medical students, instead of focusing on understanding concepts and applying them, memorizing and recalling the information is the dominant aspect of educational program (2). In training physicians, it should also pay attention to medical education and clinical skills with respect to justice, dignity and human rights. This is the ultimate goal of medical ethics (3). Some studies consider medical ethics education more 
important in the hospital than in classrooms or workshops (4). However, in some studies in course of medical ethics, the method of lecturing and teacher centered teaching have been more welcomed (5). This training alone cannot meet the needs of health care system to have specialized physicians (6).

In new methods of education, such as student-centered and problem-based learning strategies, students acquire and infer to their own knowledge and skills, and in these strategies, think about how to be selfdirected learning and take responsibility for their own learning (7). This type of learning is called selfdirected and deals with the creation of knowledge in specific areas as well as the ability to transfer general knowledge in new situations. In medical education, self-directed learning is emphasized and it is a process in which medical students determine their educational needs and identify resources for learning, select and implement learning strategies, and finally evaluate learning outcomes $(8,9)$. Lack of cognitive skills leads students to suffer, and often fail (10). Studies show that final year students are usually more self-directed than other students. Some studies have reported a degree of self-directed for students ' learning in moderate levels, some studies at high levels $(10,11)$. Self-directed people have set goals for themselves, select appropriate learning strategies, retain their motivation, monitor their performance and evaluate their progress. Zimmerman (2000) introduces this important construct in the teaching-learning process as self-regulating, focusing on and controlling the way in which the learner begins the first step in learning (12). In fact, self-regulation refers to the fact that learners can facilitate learning process regardless of their previous learning ability and by using a conducive environment (13).

Many researchers have shown that there is a relationship between self-regulatory skills and students' academic performance $(14,15)$. But Demirören et al. showed that self-regulation doesn't affect students' academic achievement (16). It seems that the realization of self-directed and self-regulation learning create the necessary ground for flourishing and discovering the talents of learners and meeting them in meeting intellectual needs, also creativity help in teaching and learning; And leads to inclusive responsibility in the process of teaching and learning $(10,17)$. Also, the use of technology along with education and use of its complementary potential in the form of blended learning is one of the effective approaches in promoting learning in medical education. This tutorial in form of different models can provide the context for qualitative improvement of education. One of the blended learning methods in this approach is the flex model in which the student is placed in designed virtual learning spaces (content, discussion, evaluation) under the guidance of the teacher and benefits from the ability of virtual space in completing his activities and learning.

Blended learning can be as an effective learning and teaching strategy for strengthening and integration basic sciences with clinical themes, and more on the result of learning to increase the process of education based on lifelong learning among medical students (18).

Also in the student-entered approach, using different methods by promoting the student's share in their learning can play a significant role in student learning. This approach emerging educational program by using technology to make these tools more user-friendly for teachers and students (19). 
Also blended leaning increases student's contribution to their learning based on constructivist approach and facilitates student's role in self-assessment and building the knowledge that he or she needs through methods such as group discussions in forums, engaging with real cases and clinical cases. Therefore, this study was conducted to investigate the comprehensive case study program of ethics course based on blended learning model on individual learning indicators (self-direction and self-regulation) and then its effect on students' knowledge.

\section{Methods}

\section{Design and setting}

This study is a quasi-experimental study with pre- and post-intervention that was conducted in the academic year of 1397_98 in Jahrom University of Medical Sciences. 70 medical students in two courses of physiopathology at Jahrom University of Medical Sciences who take the course of medical ethics participated in the study by census. All students who took the clinical reasoning tests, including forum participation and student discussion in forum, were included in the study.

This study with the code of ethics IR.SUMS.REC.1399.793 has been approved and registered in the ethics committee of Shiraz University of Medical Sciences.

All ethical considerations such as optionality of entering and leaving the study, confidentiality of information and explaining anonymity of the questionnaire, as well as obtaining students' consent from surveyed were considered

In this study, at first, the method of teaching ethics was explained based on teaching process and expressing expectations from the student in a curriculum. Based on this, how to work in the forum, participation and discussion of students in the forum - how to use principles of ethical interpretation and models to discuss a group of ethical issues and its objectives were examined and students were justified about the curriculum.

Prior to intervention, self-directed and self-regulated questionnaires were coded and given to students.

Questions were then designed to assess the level of knowledge and reasoning of students in the forum environment by presenting five case issues. It was placed in the LMS of university. Students were required to present their views on the raised according to the schedule. Questions were taught daily in the forum for up to a week (one question per day) before the main topics started. Number of questions was 5 and it was designed for 5 days. In this case, the student first answers the questions individually and find the answers of other peers that provided the ground for development of moral sensitivity and then rethinking of learners.

In the following, after teaching the lesson, the titles are determined in order by a team of professors of medical ethics. 
In the next step, after trainings, in parallel with taught concepts, a set of 40 clinical cases in the field of ethics was provided to students so that both of them could discuss their case and discuss with others in a class group discussion. In the student discussion section of the forum, 5 scenarios with ethical topics and corresponding to titles were included; and students began to study ethical issues and demonstrated their level of reasoning on the issues at hand.

The blended learning model through the use of technology in teaching and learning in the forum and use of content uploaded on LMS provided conditions for implementation of the blended learning model based on the Flex model. Accordingly, one of the training methods in this training program was to use online and offline content in the LMS space. Learning through the forum and interacting in this space contributed to more effective learning again.

The ended phases was post-test of questionnaires. Also all students filled out their portfolio based the report on the student's understanding of each teaching sessions,

Provide analysis of two ethics cases and then analysis of an ethical article .

Also all students filled their portfolio .All students were required to complete their portfolio.

The portfolio included topics such as students' personal understanding and interpretation of ethic course, analysis of two ethical cases, and then analysis of a published ethics article.

The educational design scheme of the program can be expressed as follows: 


\title{
Explanation of course
}

\author{
$\downarrow$
}

Pre-testing questionnaires

$\downarrow$

Assessing the level of knowledge

$\downarrow$

Lecture by case based discussion

$\downarrow$

Group case based discussion in class

$\downarrow$

Arranging all contents in LMs

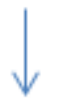

Discuss the forum

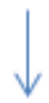

Post-testing questionnaires

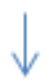

Portfolio

\section{Data collection tools:}

The self-directed questionnaire used in this study, Guglielmino Self-Readiness Scale (1978) is a selfreport questionnaire with 41 questions, 5 point Likert scales (rarely to always) that have three areas of self-management, desire to learn and self-control. The internal consistency of the questions was calculated 0.95 and the reliability of the test- retest was calculated 0.68 . The scores of each field are calculated from 100 and the scores less than 33.3 are considered low, between 33.3 to 66.7 are average and more than that are considered high. The Cronbach's alpha coefficient for subscales of selfmanagement was 0.81 , desire to learn was 0.78 and self-control was 0.84 . This questionnaire was evaluated by Nadi and Sajjadian in 2012 on 1135 medical and dental students and the validity and reliability of it were confirmed. The maximum score achieved in this tool is 205 and the minimum is 41 (20).

Another questionnaire used was Beaufort (1995) self-regulatory questionnaire which contains 14 questions that assess the level of self-regulation in individuals. The scoring method using the Likert scale 
is from strongly agree to strongly disagree. Questions 5-13-14 are scored in reverse. The minimum possible score will be 14 and the maximum will be 70 . A score between 14 and 28 indicates a low level of self-regulation, between 28 and 42 indicates a moderate level of self-regulation and above 42 indicates a high level of self-regulation. For the construct validity of Beafort self-regulatory questionnaire, the results of factor analysis showed that the correlation coefficient between questions was appropriated. (21).

The teaching effectiveness questionnaire was used to assess the student's perspective in this field.

This questionnaire contains 5 five-choice questions according to the 5-point Likert scale provided by the researcher.

In designing this questionnaire, citing research texts in the field of teaching, 6 criteria for effective teaching components were considered, including teaching design (questions 1 to 5), education (questions 6 to 10), classroom management (questions 11 to 15), Human relations (questions 16 to 20), eassessment (questions 21 to 25 ) and desirable personality traits (questions 26 to 30 ).

In fact, for each of these criteria, 5 questions and a total of 30 questions were considered. The range of scores in this questionnaire in each question was from zero to 4 . The answers of this test were adjusted on a five-point scale in the Likert scale from always to never

The lowest to highest scores ranged from zero to 20 in each of the criteria thus, the range of the lowest to the highest score of professors in a total of 6 criteria for effective teaching, from zero to 120 was considered.

Eslamian et al. obtained the validity of the questionnaire by studying and consulting a number of professors of educational sciences and researchers in the field of teaching. Also, its reliability was obtained through a retest method on 30 random samples from the main population, except for those who participated in the study and using Cronbach's alpha coefficient of 0.89(22).

Analysis of research data was performed using SPSS software at two levels of descriptive statistics using percentage and mean and analytical statistics using paired t-test and Mann-Whitney and Wilcoxon tests before and after intervention.

\section{Results}

A total of 70 medical students participated in the study. Overall $67.1 \%$ of them were girls and the rest were boys. The level of self-directed learning of more than half of the students has been at a strong level $(55.7 \%)$ which has increased to $78.6 \%$ with the intervention of ethics education. The level of self-direction in the two components was the level of desire of the majority of students to learn before and after the intervention at a strong level and increased from $70 \%$ before the intervention to $75.7 \%$ after the intervention. Also, the level of self-control of $60 \%$ of students before the intervention was moderate and $40 \%$ was weak. With the intervention of ethics education, the level of self-control of $30 \%$ of students has 
been raised to the intermediate level and $70 \%$ of students to the strong level. Also, the level of selfmanagement in this index did not increase (Table 1,2).

Table 1

Level of self-regulated learning before and after intervention

\begin{tabular}{|c|c|c|c|c|c|}
\hline \multirow[t]{3}{*}{ Self-regulated learning } & \multicolumn{5}{|l|}{ Levels } \\
\hline & Status & weak & \multicolumn{2}{|c|}{ moderate } & strong \\
\hline & Before & $7(10)$ & $14(20)$ & $49(70)$ & \\
\hline & After & $0(0)$ & $5(7.1)$ & $65(92.9)$ & \\
\hline
\end{tabular}

Table 2

Level of self-directed learning before - after intervention

\begin{tabular}{|llllll|}
\hline Self-directed learning & \multicolumn{3}{l}{ Levels } & \multirow{2}{*}{ P value } \\
\cline { 3 - 6 } & & Weak & Moderate & strong & \\
Self-management & Before & $394.3)$ & $11(15.7)$ & $56(80)$ & 0.679 \\
& After & 0 & $15(21.4)$ & $55(80)$ & \\
\multirow{2}{*}{ Desire to learning } & Before & $3(4.3)$ & $28(25.7)$ & $49(70)$ & 0.198 \\
& After & $0(0)$ & $17(24.3)$ & $53(75.7)$ & \\
Self-control & Before & $28(40)$ & $42960)$ & $0(0)$ & 0.001 \\
& After & $0(0)$ & $21930)$ & $49(79)$ & \\
\hline
\end{tabular}

Level of self-regulated learning also changed. Level of students' self-regulated learning increased in strung level after intervention (92.9\%) .

The results of paired t-test showed that the overall mean of students' self-direction after the intervention $(159 / 11 \pm 13 / 35)$ was significantly higher than before the intervention $(153 / 64 \pm 16 / 28)(p=0.005)$. But the dimensions of students 'self-direction including self-management, desire to learn and students' selfcontrol after the intervention were not significant compared to before the intervention $(p<0.05)$. However, the mean score of self-regulated learning increased after intervention with the average specified.

Although, the mean of total self-regulation was not significant despite the increase in the overall average $(p=0.149)$. (Table 3$)$. 
Table 3

The effect of a student center based on the educational program on students' self-regulation and selfgovernment

\begin{tabular}{|c|c|c|c|c|c|c|c|}
\hline \multicolumn{2}{|l|}{ Indicators } & Stages & mean & SD & Difference & $\begin{array}{l}\mathrm{p}- \\
\text { value }\end{array}$ & Test \\
\hline \multirow{2}{*}{\multicolumn{2}{|c|}{ Total score of self-direction }} & Pre & 153.64 & 16.28 & \multirow[t]{2}{*}{5.47} & \multirow[t]{2}{*}{0.005} & \multirow{2}{*}{$\begin{array}{l}\text { Paired } \\
\text { sample T } \\
\text { test }\end{array}$} \\
\hline & & Post & $159 / 11$ & 13.35 & & & \\
\hline \multirow{6}{*}{$\begin{array}{l}\text { self-direction's } \\
\text { dimensions }\end{array}$} & \multirow{2}{*}{$\begin{array}{l}\text { self- } \\
\text { management }\end{array}$} & Pre & 62.43 & 5.44 & \multirow[t]{2}{*}{0.19} & \multirow[t]{2}{*}{0.51} & \multirow{2}{*}{$\begin{array}{l}\text { Paired } \\
\text { sample T } \\
\text { test }\end{array}$} \\
\hline & & Post & 62.24 & 5.98 & & & \\
\hline & \multirow{2}{*}{$\begin{array}{l}\text { desire to } \\
\text { learn }\end{array}$} & Pre & 39.24 & 4.99 & \multirow[t]{2}{*}{0.21} & \multirow[t]{2}{*}{0.73} & \multirow[t]{2}{*}{ Wilcoxon } \\
\hline & & Post & 39.23 & 4.05 & & & \\
\hline & \multirow[t]{2}{*}{ self-control } & Pre & 47.63 & 14.81 & \multirow[t]{2}{*}{5.61} & \multirow[t]{2}{*}{0.52} & \multirow[t]{2}{*}{ Wilcoxon } \\
\hline & & Post & 53.24 & 5.37 & & & \\
\hline \multirow{2}{*}{\multicolumn{2}{|c|}{ Total score of self-regulation }} & Pre & 47.37 & 7.92 & \multirow[t]{2}{*}{1.36} & \multirow[t]{2}{*}{0.149} & \multirow{2}{*}{$\begin{array}{l}\text { Mann- } \\
\text { Whitney }\end{array}$} \\
\hline & & Post & 48.73 & 3.72 & & & \\
\hline
\end{tabular}

The effectiveness of teaching from students' view of points showed that mean score of students were high in all dimensions. Table (4).

Table 4

The effectiveness of education from the perspective of students

\begin{tabular}{|lcl|}
\hline Effective teaching components & Mean & SD \\
\hline Design & 17.57 & 0.76 \\
\hline Education & 17.24 & 0.60 \\
\hline Class management & 16.93 & 0.64 \\
\hline Human relations & 18.04 & 0.63 \\
\hline Assessment & 18.90 & 0.56 \\
\hline Desired personality traits & 18.64 & 0.65 \\
\hline Total & 107.33 & 0.76 \\
\hline
\end{tabular}

\section{Discussion}


The aim of this study was to investigate the comprehensive education of ethics course based on studentcentred educational approaches based on case study and blended approach and its effect on learning indicators of self-management and self-regulation and on the other hand students' knowledge.

The results of present study showed that a student-centred educational approach has an effect on students' self-direction. It can be reported that comprehensive ethics education caused students to take the initiative in learning in a purposeful way instead of passive behaviour, and due to high motivation, their learning will be sustainable and continuous. On the other hand, ethics education encourages students to expand their ability to assess their knowledge deficiencies and bridge the gap between scientific knowledge and real-world issues (23).

Findings of the present study were consistent with the findings of Gordan Shekan et al. (2010), Mosallanejad et al. (2014) and Kidaneh et al. $(2020)(7,17,24)$. Gordan Shekan et al. (2010)

The effect of teaching by metacognitive package on self-direction in learning of medical students of Isfahan University of Medical Sciences, used a researcher-made metacognitive package that included three sections: metacognition, problem solving and critical thinking. It showed that the researcher-made metacognitive package is effective on self-direction. The metacognitive package in their study had similarities in terms of concept and structure with the present research intervention.

Also, Mosallanejad et al. (2014) by examining the effect of a short training course in the form of team learning and examining its effect on self-directed learning and self-regulated learning of nursing students showed that educational intervention in the form of a team can strengthen students' self-direction (17).

Litamia et al. (2016) reported that problem-based learning process, assessment, learning environment, lifestyle, understanding of students' topics, have been considered as factors affecting self-directed learning (25).

Considering that in the present study, the process of teaching ethics was student-centered and the student had an effective role in constructing his knowledge, it was consistent with the findings of other research (26).

Self-directed learning can be influenced by a set of factors such as personal characteristics and their learning environment (27).

Kidane et al. (2020) reported that problem-solving method through blended learning can be enhance clinical self-directed learning in clinical students (24).

In fact, strengthening learners' self-direction in learning can be considered as the result of interaction between learners and their environment. Therefore, it is suggested that in educating students, especially in teaching ethics, pay attention to the blended learning and the use of forum discussion and the participation of students in team discussions. 
All results above confirmed the effect of teaching methods on students' self-directed learning.

Najafi (2019), showed that blended learning by compact of both traditional and modern technologies, can improve imagination, Self-regulatory, Self-motivation and learning and affect the quality of learning(28).

On the other hand, Xiaoqin Wu et al. (2020) in corona pandemic have introduced the use of e-learning technologies as a basis for development of learning in studens.but, , special learning problems such as insufficient motivation of students to and in e-learning ability of students should be given special attention $(29,30)$.

The results of the present study showed the effect of comprehensive ethics education based on studentcentered educational approaches on students' self-regulation. It can be said that the content of medical ethics curriculum and teaching strategy used in redesigning ethics education, allows students to build knowledge needed by the student and review, rethink and deep understanding of learning. These results consistent with other evidences $(17,31,32)$

Other research by interfering in self-regulated learning strategies in programming and its concepts, in computer engineering students, it was shown that students' self-regulation improves after educational intervention. As well, Virtinen et al. linked self-regulatory strategies to learning strategies (33). Raaijmakers et al. identify the type of educational intervention and the use of video modelling to be effective in improving performance and self-regulated learning (14).

Hooshyar et al. emphasized educational intervention promoted active thinking in students and also enhances self-regulated learning in online higher education learning environments (31).

Pedrosa et al. Showed that the educational intervention based on the SimProgramming approach rely on (learning assignment process and changes in specifics tasks) improved self-regulated learning strategies in students (34).

Loeffler et al. have proposed an interactive educational intervention to offer a new approach to facilitate self-regulated learning in everyday work (35).

Also short-term PBL course can be effective on self-regulated learning and conceptual learning of medical students (36).

Findings of Saks et al. (37) were not consistent with findings of present study. They showed that elearning and media-based content did not significantly change the way self-centered learning and selfregulated learning (37).

Students often demonstrate weaknesses in knowledge and the use of self-regulatory strategies and by overestimating and exaggerating their knowledge, they show that they do not need self-regulation in learning processes (38). 
Due to results above, we suggest educational strategies can be help to students to develop their skills in self-regulation process.

It can be said that traditional evaluation methods, in addition to not being appropriate for educational goals, do not have necessary efficiency to measure clinical skills and student performance and do not provide the necessary assurance about the competence of students for educators (39).

Comprehensive ethics education based on student-centered educational approaches and individual assignments in LMS, by participating in the forum and exchanging views on issues raised individually and as a team it has strengthened the level of students' learning indicators.

In line with the results of the present study, Meng et al., Use of new student-centered approaches such as self-study sessions, self-assessment, group discussions, active learning in comparison with traditional methods improved learning and performance of pharmacy students(40).

Tolsgaard et al. have also considered the teaching of clinical skills in medical education to be effective on students' learning and performance using a knowledge-based approach (41).

One of the limitations of this study was the problem of reaching students due to the busy schedule and educational rounds and their cooperation in filling out questionnaires and interviews, which was solved by visiting several times. Also, in collecting information, the questionnaires may have incomplete information that such questionnaires were excluded from the study.

\section{Conclusions}

According to the findings of the present study, comprehensive teaching of ethics based on studentcantered educational approaches through blended learning models as complementary education can affect students' self-direction and self-regulation. Also therefore, it seems that the mentioned model is one of the important and new issues that are less addressed in the country. Also this method can be considered as an appropriate method of teaching medical ethics improves students' self-directed and self-regulatory skills. However, given that this educational approach has been done to a limited extent, requires more extensive studies in multi central and other universities to assess other effect of this strategy and method on students' learning and other indicators and confirm resent results. Content development and use of new teaching methods and continuous evaluation and review should always be considered by those in charge because any shortcoming will expose the future career of students as future physicians to legal and moral risks.

\section{Declarations}

\section{Ethics approval and consent to participate}


First, the approval for the study was obtained from the ethics committee of shiraz University of Medical Sciences cod number (IR.Sums.REC.1399.793). Then, to collect the data, one of the authors distributed the questionnaires among the participants and instructed the objectives of the study and advised them on how to fill out the questionnaire. And written consent obtained from participants.

\section{Consent for publication}

Not applicable.

\section{Availability of data and material}

This datasets are available from the corresponding author on reasonable request.

\section{Competing interests}

The authors declare that they have no competing interests.

\section{Funding}

This research was funded by the research department at Jahrom University of Medical Sciences.

For financial support

\section{Authors' contributions}

LM :Design , Data collection, Analysis, Writing the first draft of the article ; SA : Critical revision of the article, R R: Critical revision of the article. All auteurs read and approved all parts of articles

\section{Acknowledgments}

We thank gratefully all students in jahrom university of Medical sciences and experts who participated in this study

\section{References}

1. Amiresmaili $M$, Nekoei Moghadam M, Moosazadeh $M$, Pahlavan EJSiDoME. Challenges of general practice education in Iran: A qualitative study. 2013;9(2):118-31.

2. Abedini z, Akhondzadeh k, hA. t. student experiences from combination of problem based learning and work in small group: a qualitative study. Journal of Sabzevar University of Medical Sciences. 
2010;17(3):8-18. [persian]

3. Khaghanizadeh M, Maleki $H$, Abbasi M, Abbaspoor AJMEJ. Identity of the medical ethics curriculum based on the experiences of teachers of medical ethics: qualitative research. 2011;5(16):95-116. [persian]

4. Ebrahimi S, Alinejad NJIJoME, Medicine Ho. The Impact of Ethics Workshop on the Ethical Knowledge and Competency of fourth Years Medical Students of Shiraz University of Medical Sciences. 2017;10(1):55-66. [persian]

5. Managheb S, Y. S-M. Methodology of teaching and evaluation of medical ethics course from the perspective of teachers. Biannual Medical Education, Babol Univ Med Sci. 2017;5(1):47-52. [persian]

6. Adel F, Ataei G. The place of ethics in Iranian medical education. J Education and Ethics in Nursing. 2012;1(1):1-7.

7. Gordanshekan M, Yarmohammadian MH, Ajami SJIJoME. The Effect of Teaching Meta-cognition Package on Self-Directed Learning in Medical Records Students of Isfahan University of Medical Sciences. 2010;10(2):131-40. [persian]

8. El-Gilany A, Abusaad F. Self-directed learning readiness and learning styles among Saudi undergraduate nursing students. J Nurse education today. 2013;33(9):1040-4.

9. Shankar R, Bajracharya O, Jha N, Gurung S, Ansari S, Thapa H. Change In Medical Students' Readiness For Selfdirected Learning After A Partially Problembased Learning First Year Curriculum At The KIST Medical College In Lalitpur, Nepal. J Education for Health. 2011;24(2):552.

10. Zaersabet F, Tabari Khomeiran R, Asadi Louyeh A, Kazemnezhad Leili EJRiME. A Survey on SelfDirected Learning Readiness Status and Its Relative Factors in Students of Guilan University of Medical Sciences. 2014;6(2):36-43. [persian]

11. Safavi M, Shooshtari S, Mahmoodi M, Yarmohammadian MH. Self-directed Learning Readiness and Learning Styles among Nursing Students of Isfahan University of Medical Sciences Iranian Journal of Med Edu. 2010;10(1):27-36. [persian]

12. Zahed A, Rajabi S, M. O. A comparison of social, emotional and educational adjustment and selfregulated learning in students with and without learning disabilities. Journal of Learning Disabilities. 2012;1(2):43-62. [persian]

13. Garshasbi A, khorsand E, Taghizadeh A. The Effect of Self- Regulation Skills Training on Academic Achievement Motivation and Academic Performance of Nursing Students in English lesson. J Research in Medical Education. 2018;10(1):9-1. [persian]

14. Raaijmakers SF, Baars M, Schaap L, Paas F, van Merriënboer J, van Gog TJIS. Training self-regulated learning skills with video modeling examples: Do task-selection skills transfer? 2018;46(2):273-90. Doi:10.1007/s11251-017-9434-0

15. Vrieling E, Stijnen S, T. B. Successful learning: balancing self-regulation with instructional planning. Teaching in Higher Education. 2018;23(6):685-700.

16. Beyaztas DI, Senemoglu N. Learning approaches of successful students and factors affecting their learning approaches. Egitim ve Bilim. 2015;40(179). 
17. Senemoglu N. College of education students' approaches to learning and study skills. Egitim ve Bilim. 2011;36(160):65.

18. Demirören M, Turan S, Teker GT. Determinants of self-regulated learning skills: the roles of tutors and students. Adv Physiol Educ. 2020;44(1):93-8. Doi:10.1152/advan.00121.2019.

19. Mosalenejad L. The Effect of a Short Course Case Study on Team Learning and its Impact on Selfdirected Learning and Self-Regulatory Learning in Students. J of Edu Development Studies Center, Shaheed Sadoughi Uni of Med Sci 2014;9:206. [persian]

20. Venkatesh S, Rao YK, Nagaraja H, Woolley T, Alele FO, Malau-Aduli BS. Factors Influencing Medical Students' Experiences and Satisfaction with Blended Integrated E-Learning. Medical Principles and Practice. 2020;29(4):396-402. Doi:10.1159/000505210.

21. Romero L, Saucedo C, Caliusco MI, Gutiérrez M. Supporting Self-Regulated Learning And Personalization Using Eportfolios: A Semantic Approach Based On Learning Paths. Int J Educ Technol H.. 2019;16(1):16. Doi:10.1186/s41239-019-0146-1.

22. Nadi MA, Sadjadian IJIJoME. Validation of a Self-directed Learning Readiness Scale for Medical and Dentistry Students. Iranian Journal of Medical Education. 2011;11(2). [persian]

23. Kadivar P. Psychology of Learning. Tehran: Samt Publication; 2009.

24. Eslamian H, Jafari Sani H, Goodarzi Z, Eslamian Z. The Relationship Between Emotional Intelligence and Implementation Of Effective Teaching Components By Faculty Members In Mazandaran University Of Medical Sciences. Iranian Journal of Medical Education. 2014;14(8):687-98.

25. Karshaky $\mathrm{H}$, Mohammadzade ghasr A, Taghizadeh $\mathrm{N}$, Geravand $\mathrm{H}$. relationship self directed learning with satisfaction education in nursing and midwifery students mashhad university. the collection of 1 st national conference education psychology articles,2012.

26. Kidane $H H$, Roebertsen $H$, van der Vleuten CP. Students' perceptions towards self-directed learning in Ethiopian medical schools with new innovative curriculum: a mixed-method study. BMC Med Educ. 2020;20(1):1-10. Doi:10.1186/s12909-019-1924-0

27. Leatemia LD, Susilo AP, van Berkel $H$. Self-directed learning readiness of Asian students: students perspective on a hybrid problem based learning curriculum. Int J Med Educ.2016; 7(1): 385-92. doi: 10.5116/ijme.582e.021b.

28. Jafari Sani H, Balochzade F, Bahmanabadi S. Relationship between skill oriented and performance oriented perceived class evaluation and self-direction on learning from the viewpoint of nursing and midwifery students of Mashhad University of Medical Sciences. J Journal of Med Educ and Dev. 2013;7(4):41-51. [persian]

29. Soltani Arabshahi SK, Naeimi L. Assessment of the current situation of - self-directed learning skills in medical students. Razi J of Med Sci. 2013;20(113):10-9. [persian]

30. Najafi $\mathrm{H}$. Comparing of the effect of Blended and Traditional teaching on Learning. rme. 2019;11(2):54-63. Doi:10.29252/rme.11.2.54. [Persian]

31. Wu X, Li Y. Improving Teaching Effects of Blended Learning by Stimulating Achievement Goals. International Seminar on Education Innovation and Economic Management (SEIEM 2020); 
china2020.

32. Yaghini O, Yamani N, Daryazadeh S, Barzegar M, Sadeghi A. Medical Students' Clerkship Exposures to Expected Clinical Skills and Comparison with the Specified Minimums. Iranian Journal of Medical Education. 2018;18(0):392-402.

33. Hooshyar D, Kori K, Pedaste M, Bardone E. The potential of open learner models to promote active thinking by enhancing self-regulated learning in online higher education learning environments. $\mathrm{Br}$. J. Educ. Technol.2019;50(5):2365-86. Doi:10.1111/bjet.12826 [persian]

34. Nami Y, Enayati T, Ashouri M. The Relationship Between Self-Regulation Approaches And Learning Approaches In English Writing Tasks On English Foreign Language Students. Procedia Soc Behav Sci. 2012;47(1):614-8. [persian]

35. Virtanen P, Nevgi A, Niemi H. Self-regulation in higher education: students' motivational, regulational and learning strategies, and their relationships to study success. Studies for the learning society. 2013;3(1-2):20-34.

36. Pedrosa D, Cravino J, Morgado L, Barreira C. Self-regulated learning in higher education: strategies adopted by computer programming students when supported by the SimProgramming approach. Production. 2017;27(SPE):1-15. Doi:10.1590/0103-6513.225516

37. Loeffler SN, Bohner A, Stumpp J, Limberger MF, Gidion G. Investigating and fostering self-regulated learning in higher education using interactive ambulatory assessment. Learn Individ Differ. 2019;71:43-57. Doi:https://doi.org/10.1016/j.lindif.2019.03.006.

38. Anantharaman LT, Shankar N, Rao M, Pauline M, Nithyanandam S, Lewin S, et al. Effect of Twomonth Problem-Based Learning Course on Self-directed and Conceptual Learning among Second Year Students in an Indian Medical College. J Clin Diagn Res. 2019;13(5):5-10. Doi:10.7860/JCDR/2019/40969.12874

39. Saks K, Leijen Ä. Distinguishing self-directed and self-regulated learning and measuring them in the e-learning context. Procedia Soc Behav Sci. 2014;112:190-8.

Doi:https://doi.org/10.1016/j.sbspro.2014.01.1155

40. Sirazieva L, Fakhrutdinova R, Kamasheva L, Leikin M. Self-Regulated Learning in Higher Education. Revista Publicando. 2017;4(13):691-9.

41. Mosalanejad L, Alipor A, Zandi B. A Blended Education Program Based on Critical Thinking and Its Effect on Personality Type and Attribution Style of the Students. Turk. online j. 2010;11(2):185-96.

42. 40.Meng X, Yang L, Sun H, Du X, Yang B, Guo H. Using a Novel Student-centered Teaching Method to Improve Pharmacy Student Learning. Am J Pharm Educ. 2019;83(2):6505-. Doi:10.5688/ajpe6505

43. Tolsgaard MG. Clinical skills training in undergraduate medical education using a student-centered approach. Dan Med J. 2013;60(8):B4690. 